\title{
Organ transplantation in HIV-infected individuals: The time has come - should there be criteria?
}

\author{
Sharon Walmsley MD
}

$\mathrm{B}$ efore the advent of highly active antiretroviral therapy (HAART), HIV and its associated infectious and malignant complications were the major causes of death in patients with HIV infection, including those with serious comorbidities involving the heart, liver or kidney (1). Consequently, therapy of the underlying liver disease, such as hepatitis $\mathrm{C}$ virus $(\mathrm{HCV})$, was often not attempted, and transplantation of scarce organs was not a consideration.

However, the landscape has clearly changed, and it is estimated that HAART has decreased morbidity and mortality in HIV-infected individuals by $70 \%$ to $80 \%(2,3)$. A recent population-based survey in France (4) found that with successful HAART (defined as a CD4 cell count greater than 500 cells $/ \mathrm{mm}^{3}$ and no HIV RNA over 10,000 copies $/ \mathrm{mL}$ in the proceeding year), the standardized mortality in HIV was 1.1 compared with the general population. Recent data from the large Data Collection on Adverse Events of Anti-HIV Drugs (DAD) study (5), a prospective study of 23,441 patients from 11 cohorts in the United States, Europe and Australia, found that the overall death rate was $1.6 / 100$ person-years, with $31 \%$ of deaths related to HIV, $15 \%$ related to liver disease and $9 \%$ related to cardiovascular disease. Both HIV- and non-HIVrelated mortality were associated with CD4 cell count depletion, suggesting a role for immunosuppression in all deaths and not just those related to HIV (6).

An increasing proportion of HIV-infected individuals in the developed world are coinfected with HCV. The highest rates - up to $80 \%$ - have been reported in some clinics in Spain. In Canada, rates of coinfection from $10 \%$ to $30 \%$ have been reported in different centres across the country (3). Therefore, end-stage liver disease (ESLD) will be a growing problem in coinfected patients in the future.

Unfortunately, despite the advances in HCV management (7), the probability of a sustained virological response (or cure) with pegylated interferon and ribavirin in genotype 1 (the most common genotype in Canada) remains at less than 30\% (8). Therefore, an increasing proportion of these patients will develop advanced liver disease and may need to be considered for transplantation.

Should HIV-infected patients with ESLD (or any end-stage organ failure) be considered for transplantation? Furthermore,

University of Toronto, Immunodeficiency Clinic, Toronto Hospital, University Health Network, Toronto, Ontario

Correspondence: Dr Sharon Walmsley, 13EN Room 218, Toronto Hospital, 200 Elizabeth Street, Toronto, Ontario M5G 2 C4.

Telephone 416-340-3871, fax 416-595-5826, e-mail sharon.walmsley@uhn.on.ca

what criteria (if any) should there be for the selection of adequate candidates? Several key questions remain unanswered $(9,10)$. Does the immunosuppression associated with transplantation accelerate HIV disease progression, or might it be beneficial if immune activation is a primary component of the pathophysiology of HIV? Are there certain immunosuppressant agents that are more appropriate for those with HIV either in the context of the disease or the potential for drug interactions with HAART? Are there certain HIV criteria that define an individual with an improved outcome? Or increased risks of harm? Is the risk for HCV reinfection and liver disease progression accelerated in those with coinfection despite transplantation? Is there an optimal HAART regimen for these patients? Should there be different considerations for prophylaxis of opportunistic infection following transplantation?

Given that this is a new and evolving field, the data upon which to make decisions are scarce. The largest series in the literature (11) involved 24 coinfected patients and determined that the 12-, 24- and 36-month survival rate of $87 \%, 73 \%$ and $73 \%$, respectively, was comparable with that of HIV-negative patients. On multivariate analysis, survival was poorer among those with postliver transplant HAART intolerance and postliver transplant CD4 cell counts of less than 200 cells $/ \mathrm{mm}^{3}$ or a viral load of greater than 400 copies $/ \mathrm{mL}$.

An abstract presented at the ninth European AIDS Conference (12) by a group from the United Kingdom described the experience of liver transplantation in 12 coinfected patients. The CD4 cell count of the surviving patients ranged from 241 cells $/ \mathrm{mm}^{3}$ to 754 cells $/ \mathrm{mm}^{3}$ and all but one had a viral load less than 50 copies/mL. In the non-HCV group, five of seven patients survived for more than 365 days (range four to 67 months). In contrast, all five HCV-coinfected patients died at a median of 161 days (range 95 to 784 days), four of whom died from complications related to recurrent $\mathrm{HCV}$ infection and sepsis.

At the 2002 Conference on Retroviruses and Opportunistic Infections (13), data were presented from a multicentre prospective study that had enrolled 10 liver transplant recipients. This was subsequently updated to 19 recipients (14) and overlaps with the Ragni series (11) cited above. The eligibility 
criteria included a lack of history of opportunistic infection, a CD4 cell count greater than 100 cells $/ \mathrm{mm}^{3}$ and undetectable HIV RNA on stable HAART. Patients were allowed to undergo liver transplant if they were unable to tolerate antiretroviral therapy, if they met other criteria, and if virological suppression post-transplant was deemed likely on the basis of antiretroviral therapy history and resistance testing. The baseline CD4 cell count was a median of 321 cells $/ \mathrm{mm}^{3}$ (range 103 cells $/ \mathrm{mm}^{3}$ to 973 cells $/ \mathrm{mm}^{3}$ ) and the median HIV RNA was less than 50 copies/mL (range of less than 50 copies $/ \mathrm{mL}$ to 115,776 copies $/ \mathrm{mL}$ ). At a median of 279 days of follow-up, patient and organ survival rates were $84 \%$.

In this edition of The Canadian Journal of Infectious Diseases and Medical Microbiology, Christie and coauthors (pages 15-18) present an opinion paper discussing the ethical and scientific issues surrounding solid organ transplantation in HIV-positive patients based on the British Columbia Transplant Society guidelines for liver transplantation. In British Columbia, HIVinfected patients are considered for transplant, and guidelines are emerging. The authors of the opinion piece argue two main points: first, the stipulation that HIV-positive patients must be on HAART and must have an undetectable viral load to be waitlisted for transplant, and second, that in the absence of data, there should not be limitations to access to therapy.

There are a total of nine centres in Canada that perform liver transplantation. Most of them do not have specific guidelines or policies for HIV-infected patients. McGill University (Montreal, Quebec) is following a modification of the University of California, San Francisco protocol noted above. One patient received a liver transplant in Canada and did not survive. Two Canadians underwent liver transplant outside of Canada, one of whom is doing well.

Given our lack of knowledge in this arena, and to enable us to make more rational decisions in the future, I would argue, unlike Christie et al, that these patients do need to be studied in the context of research. This does not mean to imply that restrictive criteria necessarily need to be applied that cannot be challenged, but rather that data on the successes and failures be carefully documented.

I agree that the absence of data does not imply evidence of failure; however, donor organs continue to be a limited commodity, and we need to use our best scientific rationale to select candidates who are most likely to benefit from such a procedure. If we choose our worse candidates initially, and the outcomes are dismal, then it is unlikely that the programs will go forward, and an unfortunate conclusion that it does not work might be made. I would also agree that strict inclusion criteria on the basis of CD4 cell count, viral load and duration of HAART are not appropriate. Rather, each case should be individualized, with the rationale behind the decisions based on the balance of risks and benefits. It makes intuitive sense that those with better immune responses and better viral control would be more likely to benefit, and it would be difficult to argue the point that a coinfected patient with ESLD who had also failed all available HAART therapies and had a CD4 cell count of less than 10 cells $/ \mathrm{mm}^{3}$ and a viral load of 500,000 copies $/ \mathrm{mL}$ would be the best candidate for a scarce resource. In contrast, a patient who was unable to tolerate HAART therapy because of the liver disease (15) but had many options available with a high likelihood of viral suppression post-transplant could make a good candidate.
Similarly, but not discussed, is the patient who has not yet required specific HIV therapy, but nonetheless has had significant morbidity from liver disease. Also, therapies continue to evolve, and the absence of available HAART when someone is first considered for transplant may change before the transplant becomes available.

Heart and kidney transplantations will also need to be considered. With the prolonged survival and dyslipidemia associated with $\operatorname{HAART}(5,6)$, rates of coronary artery disease are increased and we can anticipate seeing increased incidence of ischemic cardiomyopathy that may require transplant. There is one report (16) of a successful cardiac transplant in the literature in an individual with good HIV control. HIV nephropathy and drug-induced interstitial nephritis (tenofovir) could result in the requirement for renal transplant. Given the lesser requirement for immunosuppression and the lack of a viral etiology, these transplants may fare better in those with HIV. Indeed, from the same group reporting on liver transplant (14), the success rate for kidney transplant in those with HIV was $89 \%$ for graft survival at a median of 279 days post-transplant.

Therefore, as transplant centres get more involved in the management of coinfected patients, it is crucial that experts in HIV become involved in guideline development and individual case review. Their role would include keeping the transplant team updated on the advances in HIV management, ensuring that issues such as drug interactions are considered, and assisting with the management of post-transplant complications and drug toxicity. Further, they should also ensure that the patients continue to be reviewed while on the transplant list to ensure the issues have not changed. Although it may not be mandatory to institute protocols for the care of coinfected patients, it is nonetheless important that every case be researched to guide the future.

I agree with the conclusion of Christie et al - if HIV-positive patients satisfy all of the other criteria for liver transplantation candidacy, then they need to be considered. However, because the specific HIV-related criteria remain unclear, it is difficult to conclude that they be 'equally eligible' for transplantation. The most ethical allocation system requires simultaneous considerations of efficacy, urgency and equity: will this transplant benefit the individual and could it benefit others more? In the absence of these data, we need more research, but while collecting these data, we do need to make some rational choices on which HIV patients serve to benefit and will not be harmed, and these choices should be made on a case-by-case basis and not on the basis of strict inclusion and exclusion criteria.

The final consideration is for us to help our transplant physicians and advocate the importance of organ donation to try to expand this limited resource. We must also support research in the development of nonhuman sources of organs for xenotransplantation, support research in animal models evaluating the interactions between HIV and HCV or other viruses in the pathogenesis of organ failure, and assess novel therapies.

The time to include HIV-infected patients in transplant programs has come. We now need a multidisciplinary approach to their care so we can understand how to best utilize a scarce but potentially life-saving resource.

ACKNOWLEDGEMENTS: Dr Walmsley is supported by a career scientist award from the Ontario HIV Treatment Network. 


\section{REFERENCES}

1. Selik RM, Karon JM, Ward JW. Effect of the human immunodeficiency virus epidemic on mortality from opportunistic infections in the United States in 1993. J Infect Dis 1997;176:632-6.

2. Palella FJ Jr, Delaney KM, Moorman AC, et al. Declining morbidity and mortality among patients with advanced human immunodeficiency virus infection. HIV Outpatient Study Investigators. N Engl J Med 1998;338:853-60.

3. Public Health Agency of Canada. HIV and AIDS in Canada: Surveillance report to December 31, 2003. <www.phac-aspc.gc.ca/ publicat/aids-sida/haic-vsac1203/index.html > (Version current at January 18, 2006).

4. Lewden C, APROCO-COPILOTE Study Group. Responses to antiretroviral treatment over $500 \mathrm{CD} 4 / \mathrm{mm}^{3}$ reach same mortality rates as general population: $\mathrm{APROCO}$ and Acquitaine cohorts, France. 10th European AIDS Conference, November 17-20, 2005. Abstract PE18.4/8.

5. Friis-Moller N, Sabin CA, Weber R, et al; Data Collection on Adverse Events of Anti-HIV Drugs (DAD) Study Group. Combination antiretroviral therapy and the risk of myocardial infarction. N Engl J Med 2003;349:1993-2003. (Erratum in 2004;350:955).

6. Weber, R, Friis Moller N, Sabin C, et al. Liver-related deaths among HIV-infected persons: Data from the DAD Study. Abstract PE 18.4/7 presented at the 10th European AIDS conference, Dublin, November 2005.

7. Walmsley S, Heathcote J, and members of the multidisciplinary expert panel. Management guidelines for the HCV and HIV co-infected adult: Recommendations of a multidisciplinary expert panel. Can J Infect Dis 2001;12(Suppl A):3A-21A.
8. Torriani FJ, Rodriguez-Torres M, Rockstroh JK, et al; APRICOT Study Group. Peginterferon alfa-2a plus ribavirin for chronic hepatitis $\mathrm{C}$ virus infection in HIV-infected patients. N Engl J Med 2004;351:438-50.

9. Halpern SD, Ubel PA, Caplan AL. Solid-organ transplantation in HIV-infected patients. N Engl J Med 2002;347:284-7.

10. Fishman JA. Transplantation for patients infected with human immunodeficiency virus: No longer experimental but not yet routine. J Infect Dis 2003;188:1405-11.

11. Ragni MV, Belle SH, Im K, et al. Survival of human immunodeficiency virus-infected liver transplant recipients. J Infect Dis 2003;188:1412-20.

12. Norris S, Taylor C, McDonald C, et al. Survival in HIV-infected individuals following liver transplantation is influenced by viral co-infection: The negative impact of HCV infection. Abstract F12/5 presented at the 9 th European AIDS Conference. Warsaw, October 25 to $29,2003$.

13. Roland M, Stock P, Carlson L, et al. Liver and kidney transplantation in HIV-infected patients: A preliminary multi-site experience. Abstract 655-M presented at the 9th Conference on Retroviruses and Opportunistic Infections, Seattle, Washington, February 2002.

14. Roland M, Carlson L, Stock P. Solid organ transplantation in HIV-infected individuals. AIDS Clin Care 2002;14:59-63.

15. Sulkowski MS, Thomas DL, Chaisson RE, Moore RD. Hepatotoxicity associated with antiretroviral therapy in adults infected with human immunodeficiency virus and the role of hepatitis C or B virus infection. JAMA 2000;283:74-80.

16. Calabrese LH, Albrecht M, Young J, et al. Successful cardiac transplantation in an HIV-1-infected patient with advanced disease. N Engl J Med 2003;348:2323-8. 


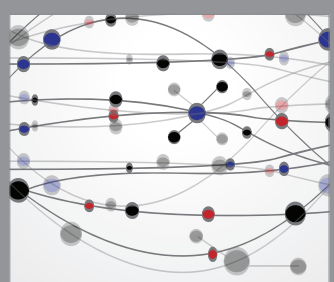

The Scientific World Journal
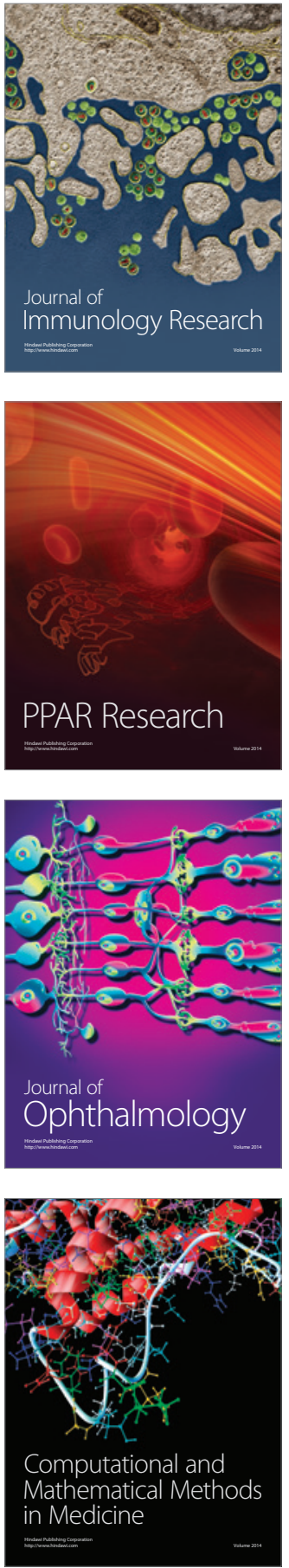

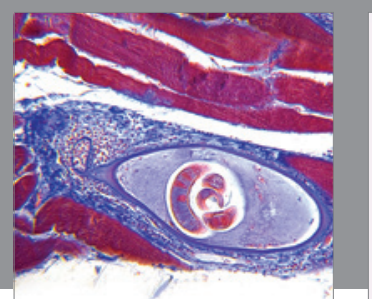

Gastroenterology Research and Practice

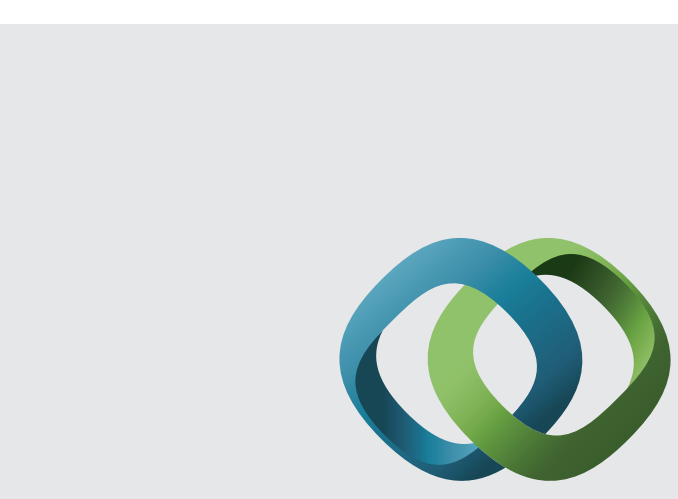

\section{Hindawi}

Submit your manuscripts at

http://www.hindawi.com
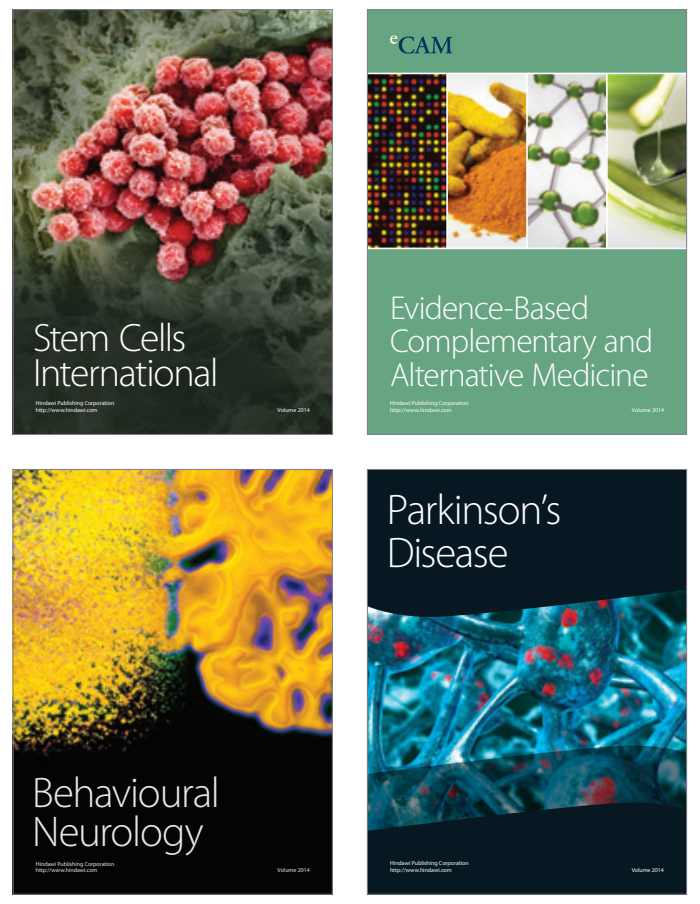
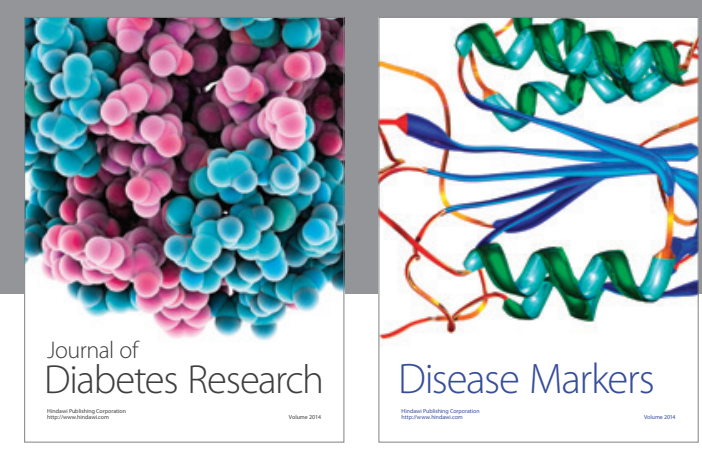

Disease Markers
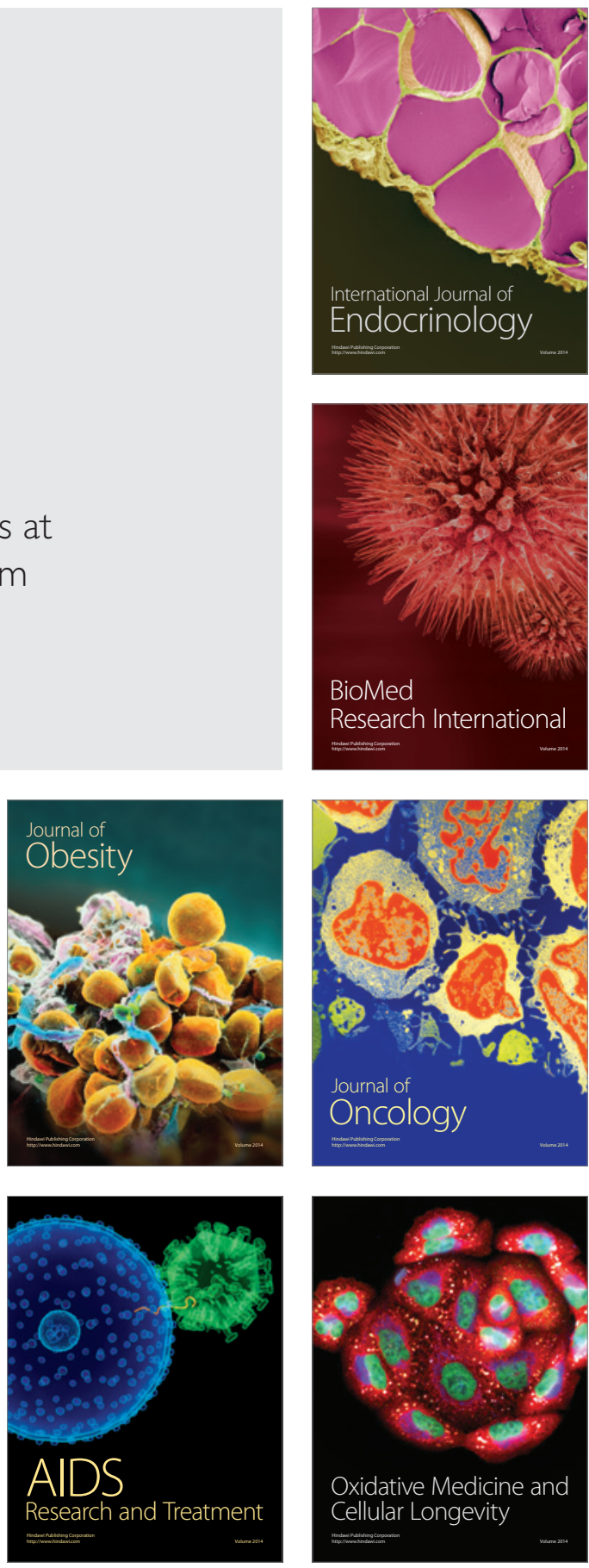